\title{
Study of Her2/neu Expression in 100 Cases of Uterine and Cervical Carcinoma as a Prognostic Marker
}

\author{
Mandakini M Patel, Rhuta J Shah* and Gurvinder Singh Saini
}

Govt. Medical College, Surat, Veer Narmad South Gujarat University, Gujarat, India

\begin{abstract}
Background: HER-2/neu, is a gene localized on chromosome 17q21 that encodes a growth factor receptor like molecule with tyrosinekinase activity. Its expression has been detected in several human cancers and is believed potential. Aim of our study was to evaluate the expression of Her-2/neu oncogene in uterine \& cervical carcinomas and determine its correlation with histological type of malignancy, grade and clinical stage of presentation.

Methods: Total 100 cases were studied, out of which there was 22 cases of uterine tumour and 78 cases of cervical tumours. The specimens were processed routinely, stained with standard H\&E method and relevant panel of immunohistochemical antibodies were applied (PAP -peroxidase anti- peroxidase method )after thorough histopathological analysis.

Result: Her-2/neu was expressed by 3 (13.6\%) out of 22 cases of uterine adenocarcinomas while in cases of cervical carcinomas 9 ( $11.53 \%) 1$ out of 78 cases express Her-2neu. In cervical carcinoma, 50\% cases of squamous cell carcinomas, $20 \%$ poorly differentiated carcinomas, $18.1 \%$ well differentiated carcinomas and $3.4 \%$ of moderately differentiated carcinomas express Her- $2 /$ neu positivity.

Conclusion: We have found that Her-2/neu can be used as a prognostic marker in uterine carcinoma and its expression increases with increase in stage and grade of endometrial adenocarcinoma. Her $2 /$ neu has little utility in cervical carcinomas and is not correlated with its grading and staging.
\end{abstract}

Keywords: Her2/neu, Uterine Carcinoma, Cervical Carcinoma

\section{Introduction}

Cervical cancer is the commonest gynecological malignancy in developing countries. Risk factors for cervical cancer are early marriage, early childbirth, multiparity, poor hygeine and chronic infection with sexually transmitted disease. Sexually transmitted human papilloma virus (HPV) infection is the most important risk factor for cervical intraepithelial neoplasia and invasive cervical cancer. ${ }^{[1]}$

Corpus cancer is commoner in developed countries than developing countries. Majority of women present with either postmenopausal bleeding prior to being diagnosed as endometrial cancer. It is a hormone dependent cancer and is associated with several epidemiological risk factors, the most significant of which include unopposed estrogen, obesity, diabetes, hypertension, and infertility. ${ }^{[2,3]}$ The present study was conducted to evaluate the presence of Her-2/neu in lesions of the uterus and cervix, its pattern of expression and correlation with histological type, grade of tumor and clinical stage. HER-2/neu, is a gene localized on chromosome $17 \mathrm{q} 21$ that encodes a growth factor receptor like molecule with tyrosine- kinase activity and has a structure similar to that of epidermal growth factor receptor. ${ }^{[4,5]}$ Its expression has been detected in several human cancers and is believed potential.

Aims and Objectives: To evaluate the expression of Her-2/neu oncogene in uterine \& cervical carcinomas and determine its correlation with histological type of malignancy, grade and clinical stage of presentation in uterine \& cervical carcinomas.

\section{Materials and Methods}

The present study was conducted in the Department of Pathology, at Tertiary Care Centre in South Gujarat. The cases included were specimens sent from Department of Obstetrics and Gynecology at same tertiary care centre from August 2012 to October 2014. Total 100 cases were studied, out of which there were 22 cases of uterine tumour and 78 cases of cervical tumours. Specimens were Total hysterectomy,Subtotal hysterectomy, Endometrial biopsies, Dilation and curettage \& Endocervical biopsies. Grossing and reporting were done according to the $\mathrm{CAP}($ College of American Pathologists) protocol for the examination of specimens from patients with uterine and cervical specimen. The specimens were processed routinely and were stained with standard hematoxylin and eosin (H\&E) method and relevant panel of immunohistochemical antibodies 
were applied after thorough histopathological analysis. IHC technique used was based on PAP (peroxidase antiperoxidase) method.

Reporting Immunohistochemical Results of Her-2-neu ${ }^{[5]}$

\section{IHC Score Criteria}

0 (Negative) Noimmunoreactivity orimmunoreactivity in $\leq 10 \%$ of tumor cells

$1+$ (Negative) Faint weak immunoreactivity in $>10 \%$ of tumor cells but only a portion of the membrane is positive.

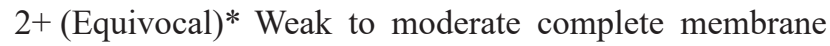
immunoreactivity in $10 \%$ of tumor cells or circumferential intense membrane + staining in $\leq 30 \%$ of cells

$3+$ (Positive) More than 30\% of the tumor cells must show circumferential intense and uniform membrane staining. A homogeneous (chicken wire) pattern should be present.

* Equivocal cases were advised FISH, but were included as negative in the present study

Only tumor cells stained in the appropriate cytoplasmic/ membrane/nuclear position were scored. Focal staining was interpreted as positivity in $\leq 50 \%$ of the cells $(1+, 2+)$. Diffuse staining was interpreted as positivity in $>50 \%$ of the cells $(3+)$ For statistical analysis cases with any degree of positive staining (focal or diffuse) were considered positive. Appropriate controls (breast with previous +3 positivity) were included. In present study, weak/ moderate/strong staining considered as positive staining and equivocal staining considered as negatives. Her-2/neu takes membranous staining(figure1)

\section{Result}

In present study 100 cases are included out of which 22 cases were uterine carcinomas and 78 were of cervical carcinomas. In present study, majority of cases of uterine cancer is present in elder age group. Most common age of presentation is $46-50$ year (18\%). In present study all $22 \%$ uterine cases were endometrial adenocarcinoma Majority of endometrial adenocarcinomas were included in the study group were endometrioid variant ${ }^{[14]}(64 \%)$, followed by villoglandular ${ }^{[5]}(23 \%)$, serous ${ }^{[2]}(9 \%)$ and clear cell variant ${ }^{[1]}(4 \%)$. Out of 78 cases of cervical carcinoma, $51 \%$ cases were squamous cell carcinomas, 21 $\%$ endocervical adenocarcinomas, 4\% carcinoma in situ, $1 \%$ poorly differentiated carcinoma and $1 \%$ undifferentiated carcinoma

As shown in table 1, Her-2/neu was expressed by 3 (13.6\%) out of 22 cases of uterine adenocarcinomas while in cases of cervical carcinomas $9(11.53 \%)$ out of 78 cases express Her-2neu .

In present study out of $51 \%$ cases of squamous cell carcinomas, $20 \%$ poorly differentiated carcinomas, $18.1 \%$ well differentiated carcinomas and $3.4 \%$ of moderately differentiated carcinomas express Her-2/neu positivity (table 2)

In current study grading of her-2/neu was done in different grades of uterine and cervical adenocarcinomas. $33.3 \%$ uterine adenocarcinomas in grade I showed, +1 Her-2/ neu positive, while $66.6 \%$ cases of grade III, expressed +3 positivity. $33.3 \%$ cases of grade I cervical adenocarcinoma showed +3 her- $2 /$ neu expression, while $33.3 \%$ of grade II showed +1 and +2 positivity respectively.

Table 3 shows Her-2/ neu expression in various histological variants of uterine and cervical carcinoma

\section{Discussion}

Total 100 cases were studied, out of which $22 \%$ cases were uterine carcinomas and $78 \%$ cases were of cervical carcinomas. Uterine \& cervical carcinomas were more common in the $4^{\text {th }}-5^{\text {th }}$ decade of life $(70 \%)$, and in post menopausal period $(80 \%)$. This is comparable with the study done by Rose et al. ${ }^{[6]}$ This can be explained on

Table 1: Her-2/neu expression in uterine and cervical carcinomas

\begin{tabular}{|c|c|c|c|c|}
\hline Marker & \multicolumn{2}{|c|}{ Uterine carcinoma } & \multicolumn{2}{c|}{ Cervical carcinoma } \\
\hline & Positive & Negative & Positive & Negative \\
\hline Her-2/neu & $(3) 13.6 \%$ & $(19) 86.4 \%$ & $(9) 11.53 \%$ & $(69) 88.47 \%$ \\
\hline
\end{tabular}

Table 2: Her-2/neu expression in Squamous cell carcinomas:

\begin{tabular}{|l|c|c|}
\hline Squamous cell carcinoma & Positive & Ner-2/neu \\
\hline Well differentiated $(n=11)$ & $2(18.1 \%)$ & $9(81.9 \%)$ \\
\hline Moderately differentiated $(n=29)$ & $1(3.4 \%)$ & $28(96.6 \%)$ \\
\hline Poorly differentiated $(n=10)$ & $2(20 \%)$ & $8(80 \%)$ \\
\hline
\end{tabular}


Table 3: Her-2/neu expression in variants of uterine and cervical carcinoma

\begin{tabular}{|c|c|c|c|c|c|c|c|c|c|}
\hline Her-2/ & \multicolumn{4}{|c|}{ Endometrial Carcinoma } & \multicolumn{5}{|c|}{ Cervical Carcinoma } \\
\hline 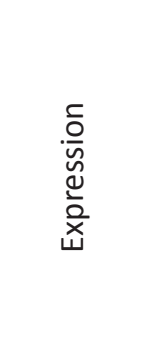 & 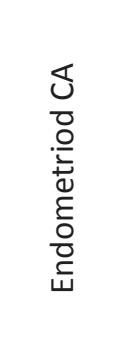 & 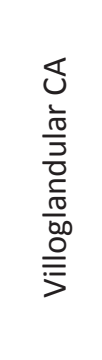 & 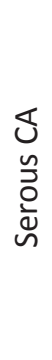 & 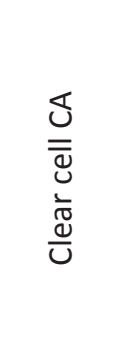 & 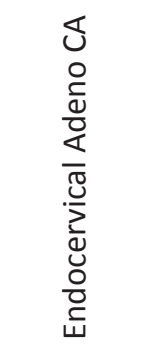 & 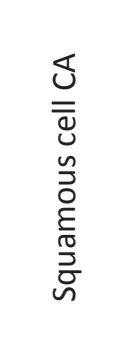 & 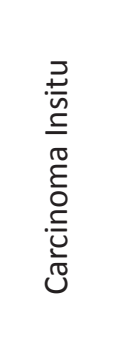 & 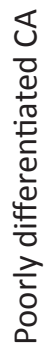 & 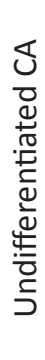 \\
\hline \multirow[t]{2}{*}{ Positive } & 1 & 1 & 0 & 1 & 3 & 5 & 1 & 0 & 0 \\
\hline & [7.1\%] & [20\%] & & [100\%] & [14.2\%] & [9.8\%] & [25\%] & & \\
\hline \multirow[t]{2}{*}{ Negative } & 13 & 4 & 0 & 0 & 18 & 46 & 3 & 0 & 0 \\
\hline & [92.8\%] & [80\%] & & & [85.71\%] & [90.1\%] & [75\%] & & \\
\hline Total & 14 & 5 & 2 & 1 & 21 & 51 & 4 & 1 & 1 \\
\hline
\end{tabular}

Table 4: Comparison of expression of Her-2/neu in cervical cancer in present study with Gupta et al:

\begin{tabular}{|c|c|c|}
\hline Her-2/neu Expression & Gupta et al. & Present study \\
\hline Squamous cell carcinoma & $54 \%$ & $12 \%$ \\
\hline Adenocarcinoma & $84.6 \%$ & $14.2 \%$ \\
\hline Adenosquamous & $100 \%$ & $100 \%$ \\
\hline Carcinoma in situ & $60 \%$ & $25 \%$ \\
\hline
\end{tabular}

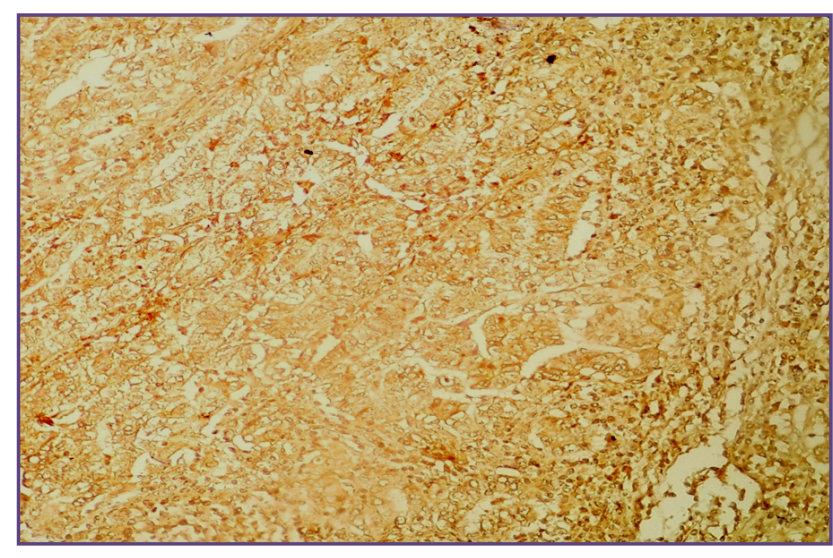

Fig. 1: showing diffuse membranous positivity with HER$2 /$ neu. $40 \mathrm{X}$

the basis of oestrogen excess. In cases of squamous cell carcinomas, bleeding per vagina and growth is the most common presenting complain, this was comparable with the study done by uzoigwe et al. ${ }^{[7]}$ In our study bleeding was the most common presenting complaint in cases of uterine adenocarcinoma (60\%) in postmenopausal period. Rose at $\mathrm{al}^{[6]}$ also noted the same finding.
Out of 22 cases of endometrial adenocarcinoma, endometrioid (64\%) was the most common followed by villoglandular $(23 \%)$, serous and clear cell variants. It was comparable with study done by clement $\mathrm{PB}$ et al. ${ }^{[8]}$ Among 78 cases of cervical cancers included in study, 51 cases were squamous cell carcinomas followed by 21 cases of cervical adenocarcinoma, 4 cases of carcinoma in situ, 1 case of poorly differentiated carcinoma and 1 case of undifferentiated carcinoma. These findings are comparable to study done by Cannistra et al. ${ }^{[9]}$ Moderately differentiated squamous cell carcinomas was the most common squamous cell carcinoma in present study group followed by poorly and well differentiated squamous cell carcinoma, It were similar to those mentioned in WHO. ${ }^{[10]}$

Similar study done by Gupta et $\mathrm{al}^{[11]}$ showed no expression of Her-2neu in well differentiated variant while 54.5\% cases of moderately differentiated variant and $80 \%$ of poorly differentiated variant express Her-2/neu.

There is wide variation with regards to comparison of expression of Her-2 neu oncoprotein in various grades of squamous cell carcinomas in present study with Gupta et $\mathrm{a}^{[11]}$. This variation in result can be explained through 
1. Study by Mitra et $\mathrm{al}^{[12]}$ and Berchuck eta $\mathrm{al}^{[13]}$ who observed HER-2 positivity in invasive carcinoma of cervix ranged from $14-100 \%$

2. Study by Rosty et al ${ }^{[14]}$ and Califano et al ${ }^{[15]}$ revealed that over-expression of Her-2/neu is uncommon in invasive cervical carcinoma and expression of the oncogene does not appear to be related to prognosis or treatment outcome.

3. Others factors - Heterogenicity of lesion and technical problem with Antigen retrieval, availability of different antibodies for detection of markers, Inappropriate sample selection, staining technique and poor preservation of specimen also play a key role in immunohistochemistry.

Table 4 shows comparison of expression of Her-2/neu in various histological types of cervical cancer in present study with Gupta et al ${ }^{[11]}$. Results are $100 \%$ concordant with Adenosquamous Carcinoma. While there are variation in her2neu expression noted with Squamous cell Carcinoma, Adenocarcinoma, and Carcinoma Insitu.

This difference may be due to various factors which will affect the outcome of Her-2/neu expression some of which are discussed below ${ }^{[16]}$

1. It may be due to Heterogenecity of lesions or technical problem with antigen retrieval.

2. Her-2/neu has a complex activation pathway and its expression is controlled not only by the degree of gene amplification but also by several other factors like gene receptor alteration and rate of gene transcription, which help in tyrosine kinase activation leading to cellular transformation.

3. Cellular proliferation may be inhibited either by a monoclonal antibody directed toward HER-2/neu receptors extracellular domain (ECD) or message truncation secondary to alternate splicing of receptor mRNA.

4. Steroid hormones can also modulate gene expression by direct binding of hormone receptor complexes to specific DNA regulating sites.

Modification in any of these factors can alter the overexpression of HER-2/neu, thus altering the positive rates on immunostaining in various malignant neoplasms including carcinoma cervix

While $66 \%$ of endocervical adenocarcinomas were well differentiated and were included in grade I followed by grade II and grade III, it was comparable with findings of Blausteins. ${ }^{[17]}$
Her-2/neu expression in uterine adenocarcinomas

- In Current study on expression of c-erbB-2 in uterine and cervical adenocarcinoma, 6 tumours (13.9\%) out of 43 cases, expresses Her-2/neu. Similar study conducted by Lee. at al ${ }^{[18]}$ on expression of Her-2/neu found that 11 tumours $(29.7 \%)$ out of 31 cases showed expression of c-erb-B2. This disconcordance may be because of small sample size, sample selection or variable availability of kit.

- In Present study Her-2/neu was expressed in 3 (13.6\%) out of 22 cases of endometrial adenocarcinomas. Rolitsky et. $\mathrm{Al}^{[19]}$ Studied overexpression of HER-2/ neu in endometrial adenocarcinoma found that 12 (17\%) out of 72 cases showed overexpression of HER-2/neu. This is comparable with our present study. Her-2/neu expression is common in uterine adenocarcinomas and its expression varies with the variant of adenocarciomas.

- This variation can be explained by fact that study done by Nevin et al. ${ }^{[20]}$ suggesting that HER-2/neu is directly related with higher grade and more aggressive tumour, and having poor prognosis. Variation may be due to the number of higher grade of uterine carcinomas.

- In present study Her-2/neu expression was detected in $9 \%$ of uterine adenocarcinoma in grade I and $14.2 \%$ in grade III. This is comparable with study done by Carl Morrison et al.

Her-2/neu expression increases with increase in grade of the tumour this might be reason why some higher grade tumour shows her-2/neu expression.

\section{Conclusion}

Immuno-histochemistry helps in confirming as well as supporting the diagnosis. We have found that Her-2/neu can be used as a prognostic marker in cases of uterine carcinomas while it has little utility in cervical carcinomas. Her-2/neu expression increases with increase in stage and grade of endometrial adenocarcinomas, decreases with increase in grade of cervical adenocarcinoma while it is not correlated with cervical squamous cell carcinomas.

\section{Acknowledgements}

We acknowledge the support of our Departmental Head, and technical staff involved in Histopathology processing and immunohistochemistry techniques

\section{Reference}

1. Schiffman M, Castle PE, Jeronimo J, Rodriguez AC, Wacholdar S. Human papillomavirus and cervical cancer. Lancet. 2007;370(9590):890-907 
2. Gehring PA, Cantrell LA, Shafer A, Abaid LN, Mendivil A, Boggress JF. What is the optimal minimally invasive surgical procedure for endometrial cancer staging in the obese and morbidly obese women?. Gynecol Oncol. 2008:111;4-45

3. Solimen PT, Oh JC, Schmeler KM, Sun CC, Slomovitz BM, Gershenson DM, Burke TW, Lu KH. Risk factors for young premenopausal women with endometrial cancer. Obstet Gynecol. 2005:105:575-580

4. Nevin J. Laing D, kaye P, MuCulloch T, Barnard R, Silcocks $\mathrm{P}$, et al. The significance of Erb - b2 immunostaining in cervical cancer. Gynecol Oncol 1999:73:35 4-8.

5. Brunelli M, Manfrin E, Martignoni G, Bersani S, Remo A, Reghellin D, et al. HER-2/neu assessment in breast cancer using the original FDA and New ASCO/CAP guideline recommendations. Impact on selecting patients for Herceptin therapy. Am J Clin Pathol 2008;129;907-11

6. Rose PG: Endometrial carcinoma. $N$ Engl $J$ Med. 1996; 335:640-649.

7. Uzoigwe S., Seleye Fubara D.; Cancers of uterine cervix in port Harcourt, River state-a 13 year clinicopathological review; Niger J Med.2004 Apr-Jun;13(2):110-3.

8. Clement PB: Pathology of the uterine corpus. Hum Pathol 1991; 22:776-791.

9. Smedts F, Ramaekers F, Troyanovsky S, et al. Basal-cell keratins in cervical reserve cells and a comparison to their expression in cervical intraepithelial neoplasia. $\mathrm{Am} \mathrm{J}$ Pathol 1992; 140:601-61

10. Tavassoli F.A, Devilee P. (Eds.): World Health Organization Classification of Tumours. Pathology and Genetics of Tumours of the Breast and Female Genital Organs. I ARC Press: Lyon 2003:4;698-702.

11. Gupta N, Singh S, Marwah N, Kumar S, Chabra S, Sen R et al. HER-2/neu expression in lesions of uterine cervix: Is it reliable and consistent?. Indian Journal of pathology and microbiology 2009;52(4):482
12. Mitra AB, Murty VV, Pratap M, Sodhani P, Chaganti RS. EBBB2 (HER-2/neu) oncogene is frequently amplified in squamous cell carcinoma ofuterine cervix. Cancer Res 1999;54:637-9.

13. Berchuck A, Rodriguez G, Kamel A, Soper JT, ClarkePearson DL, Bast RC Jr. Expression of epidermal growth factor receptor and HER-2/neu in normal and neoplastic cervix, vulva and vagina. Obstet Gynecol1990;76:381-7

14. Rosty C, Couturier J, Vincent-Salomon A, Genin P, Fréneaux $\mathrm{P}$,Sigal-Zafrani $\mathrm{B}$, et al. Overexpression/amplification of HER-2/neu is uncommon in invasive carcinoma of the uterine cervix. Int J Gynecol Pathol 2004;23:13-7.

15. Califano D, Losito S, Pisano C, Santelli G, Greggi S, Iodice $\mathrm{F}$, et al.Significance of erb-B2 immunoreactivity in cervical cancer. Front Biosci 2006;1:2071-6.

16. Tsuda H, Hirohashi S, Shimosato Y, Tanaka Y, Hirota $\mathrm{T}$, Tsugane $\mathrm{S}$, et al.Immunohistochemical study on over expression of C-erb B2 protein in human breast cancer.Its correlation with gene amplification and long term survival of patients. Jpn J Cancer Res 1990;81:327-32.

17. Lora Ellenson . Brigitte M . Robert A . Richard J.Robert J. K. Endometrial Carcinoma.in Kumar R, Ellienson L, Bonnett B. Blausteins pathology of female genital tract: Vol-6, springer, New York 2012;400-403.

18. Lee.S, Kim. Hyung, Jung J, Lee min, Park C. Expression of vascular endothelial growth factor in adenocarcinomas of the uterine cervix and its relation to angiogenesis and p53 and c-erb B - 2 protein.Gynecologic ocology june 2002;V 85(3): 469-75.

19. Rolitsky CD, Theil K S, Mc Gaughy VR, Copeland LJ, Niemann TH.; Her-2/neu amplification and overexpression in endometrial carcinoma; Int J Gynecol Pathol1999; Apr;18(2);138-43.

20. Nevin J, Laing D, Kaye P, McCulloch T, Barnard R, Silcocks $\mathrm{P}$, et al.The significance of Erb-b2 immunostaining in cervical cancer. Gynecol Oncol 1999;73:354-8.

*Corresponding author:

DR Rhuta J Shah, Navkar, Opp. Deep Kiran Appt. Bhagyoday Soc. Chala, Vapi-396191, Taluka-Vapi, dist-Valsad, State, Gujrat (India)

Phone: +91 9428159081

Email: dr.rhutashah@gmail.com

Financial or other Competing Interests: None. 